\title{
A FORMA E A FESTA: HOMENAGEM A NORBERTO LUIZ GUARINELLO*
}

\author{
Ana Teresa Marques Gonçalves
}

\begin{abstract}
Resumo: Com grande prazer, homenageamos o professor Norberto Luiz Guarinello e sua carreira acadêmica, após sua aposentadoria como docente junto à Universidade de São Paulo. Tendo sido nosso orientador de Doutorado, optamos por fazer um breve depoimento sobre a sua importância no desenrolar de nossa própria carreira acadêmica, bem como relevamos a publicação de um artigo sobre as formas da História, com o qual, por vezes, abrimos nosso curso de História Antiga, ministrado na Universidade Federal de Goiás, onde trabalhamos há mais de 25 anos, bem como um capitulo dos Anais do Seminário Internacional "Festa: cultura e sociabilidade na América Portuguesa”, realizado na USP em 1999, que resultou na publicação, em dois volumes, de boa parte das comunicações lá apresentadas. Dentre elas, destacamos a realizada pelo professor Norberto Guarinello, intitulada "Festa, trabalho e cotidiano", que muito nos auxiliou em nossas pesquisas sobre festejos e cerimônias no Mundo Romano Antigo.
\end{abstract}

Palavras-Chave: festa; homenagem; cerimônia; ritual; Roma.

\section{FORM AND PARTY: TRIBUTE TO NORBERTO LUIZ GUARINELLO}

\begin{abstract}
With great pleasure, we honor the academic career of Professor Norberto Luiz Guarinello, after his retirement from teaching at the University of São Paulo. Having been our Doctoral advisor, we chose to make a brief statement of its importance in the course of our own academic career, as well as highlighting the publication of an article on the forms of History, with which we sometimes open our History course. Former, taught at the Federal University of Goiás, where we have been working for more than twenty-five years, as well as a chapter in the Proceedings of the International Seminar "Party: Culture and Sociability in Portuguese America",
\end{abstract}

\footnotetext{
* Recebido em: 15/07/2020 e aprovado em: 30/09/2020.

** Professora titular de História Antiga na Universidade Federal de Goiás. Doutora em História pela Universidade de São Paulo. Coordenadora do Leir-GO. Bolsista Produtividade II do CNPq. E-mail: anateresamarquesgoncalves@gmail.com. Orcid: https://orcid.org/0000-0001-6020-3860.
} 
held at USP in 1999, which resulted in publication in two volumes of most of the communications presented there. Among them, we highlight the one carried out by Professor Norberto Guarinello, entitled "Party, Work and Daily Life", which greatly helped us in our research on celebrations and ceremonies in the Ancient Roman World.

Key words: party; tribute; ceremony; ritual; Rome.

Em poucas oportunidades apareceram, em mais de 25 anos de carreira acadêmica, ocasiões em que pudéssemos optar pelo uso da primeira pessoa do singular no início de um artigo. Acabamos sempre por usar a primeira pessoa do plural na elaboração do texto, como forma convencional de ressaltar que partilhamos de uma opinião também defendida por outros expoentes do mundo acadêmico de pesquisa e docência no qual nos inserimos. Como tornou-se convenção, nem refletimos acerca da adequação dessa opção estilística, pois nem parece uma escolha, visto que, em tantos anos escrevendo artigos e ministrando aulas, introjetamos esse artifício retórico de tal forma que o naturalizamos em sua expressão textual. Contudo, neste artigo, que se inicia com um tom ensaístico, produzido em homenagem ao nosso mestre e amigo Norberto Luiz Guarinello, recém-aposentado de sua atividade docente, empreendida junto à Universidade de São Paulo, começamos o texto utilizando um "eu" sonoro, pois queremos enfatizar toda a pessoalidade que impregna o relato que começamos a desenvolver, como forma de fazer eco a todas as loas e a todos os elogios dos quais o professor se mostra receptor nessa efeméride, sublinhada pela produção deste dossiê, organizado pelo amigo professor Deivid Valério Gaia, no interior da revista Phoînix, do Lhia da Universidade Federal do Rio de Janeiro.

Conheci Norberto Guarinello nos idos da década de 90 do século XX, quando fazia Graduação em História na UFRJ. Professores e alunos do Museu de Arqueologia e Etnologia da USP, capitaneados pela doutora Haiganuch Sarian, aceitaram o convite das professoras Neyde Theml, Norma Musco Mendes e Maria Sonsoles Guerras, responsáveis à época pela condução do então Setor de História Antiga e Medieval da UFRJ, para oferecer um minicurso sobre o uso da cultura material na formação do saber histórico. Passamos a ter aulas às tardes, por várias semanas, com docentes que dominavam o saber arqueológico, e que nos ensinaram as técnicas para nos apropriarmos devidamente das informações que poderiam ser adquiridas com a pesquisa, usando dados de artefatos estudados pela Arqueologia. 
Utilizando o acervo do recém-destruído, por um incêndio de grandes proporções, Museu Nacional da Quinta da Boa Vista, e as peças, principalmente numismáticas, guardadas no Museu Histórico Nacional da Praça Marechal Âncora, aprendemos como extrair informações sobre a Antiguidade Clássica de estátuas de terracota, de ânforas de azeite e vinho, de moedas, de artefatos de bronze, de mosaicos, de pinturas parietais pompeianas, de inscrições epigráficas e de um tipo específico de cerâmica, cozida em fornos que alcançavam altas temperaturas, o que tornava a peça mais difícil de quebrar, mas bem enegrecida em sua coloração. Essas peças eram desenvolvidas principalmente pelos etruscos, que ocupavam o norte da Península Itálica, e conhecidas como a cerâmica de Bucchero.

Esse foi o módulo oferecido no minicurso pelo professor Guarinello, então recém concluindo sua dissertação de Mestrado sobre a elaboração de tal cerâmica, sob a orientação da doutora Haiga. Como adorei sua disciplina, sua metodologia de ensino e sua simpatia, acabei por descobrir que ele acabara de passar no concurso para professor universitário na USP e que estava produzindo uma tese de Doutorado, também no MAE-USP e novamente sob a orientação da doutora Haiga, na qual estudava o mundo rural romano e as plantas das villae latinas. Lembro-me, como se fosse hoje, de me virar ao final do curso para meu companheiro de Graduação na UFRJ, Gilvan Ventura da Silva, hoje docente na Universidade Federal do Espírito Santo, e afirmar categoricamente que faria Mestrado sob a orientação daquele jovem professor na USP. O problema é que o professor Norberto Guarinello tem seu tempo próprio de produção e, quando terminei a minha Graduação, ele ainda não defendera sua tese e, portanto, ainda não podia integrar o corpo docente do Programa de Pós-graduação em História da USP. Decidida a migrar para São Paulo a qualquer custo e ingressar nas hostes uspianas, fiz meu Mestrado sob a orientação da doutora Maria Luíza Corassin. Como ela integrou a banca de defesa de Doutorado de Guarinello, acabei podendo assistir a esse evento. Foi uma banca difícil, pois, além da doutora Corassin, a integraram os doutores Ciro Flamarion S. Cardoso, Ulpiano Bezerra de Menezes e Pedro Paulo A. Funari. Guarinello brilhou mais uma vez e se intensificou em mim o desejo de continuar na USP e de ser sua orientanda no Doutorado.

Porém, como chegar até ele? O professor lembraria daquela jovem monitora de História Romana da UFRJ, que ele conhecera entre vários discentes de um minicurso oferecido tantos anos atrás? Enquanto formulava uma 
estratégia para abordá-lo, de forma que ele não pudesse me recusar como orientanda, participei de uma reunião da Sociedade Brasileira de Estudos Clássicos, realizada em Garibaldi, nas serras do Rio Grande do Sul. Nesse evento, conheci pessoalmente o primeiro orientando de Guarinello, Fábio Faversani, hoje atuando academicamente na Universidade Federal de Ouro Preto. Apresentei-me ao atual querido amigo e pedi, na caradura, que ele me apresentasse ao professor mais uma vez. Com a indicação do Fábio, as portas se abriram. Guarinello aceitou me orientar e realizou o sonho de uma jovem pesquisadora. Com ele, aprendi a gentileza no trato com os orientandos, que mantenho ativa até hoje, pois creio ser prática salutar na relação pedagógica de ensino-aprendizagem, e a confiança numa leitura atenta e precisa de todos os trabalhos entregues para avaliação.

De orientador no Doutorado, o professor Norberto Guarinello transformou-se num amigo querido e num modelo profissional do qual lanço mão às vezes como instrumento pedagógico. Em várias oportunidades, cito para meus alunos fatos ocorridos em bancas e em eventos dos quais ele participou. Na construção da minha carreira, ele ajudou na pavimentação de um caminho mais seguro, indicando-me alguns buracos que podiam ser evitados e lançando luz sobre entroncamentos mais perigosos. Até hoje, ele aceita integrar bancas de orientandos meus no Programa de Pós-graduação em História da Universidade Federal de Goiás e participar de eventos realizados nessa instituição. Sua última vinda ao território goiano se deu em março do ano passado, como integrante da minha banca para promoção a Professora Titular na UFG. Nessa cerimônia, na qual defendi tese que acabei de publicar, pude expressar novamente meu carinho e minha admiração pelo grande profissional que Guarinello sempre foi. E por capricho do destino, trabalho hoje na UFG com outra orientanda de Doutorado do professor, minha estimada amiga Luciane Munhoz de Omena. De igual maneira, fruto de um fatum buliçoso, dois irmãos "em armas" e companheiros de bons e maus momentos também acabaram finalizando seus Doutorados sob a orientação dele: Gilvan, já citado, e Margarida Maria de Carvalho, que desenvolve sua carreira acadêmica na Universidade Estadual Paulista - campus de Franca. Por essas reminiscências, posso confirmar a atuação de Norberto Guarinello como um dos maiores formadores de pesquisadores e docentes na Área de História Antiga no Brasil. Dessa forma, ele acabou fomentando a expansão dos profissionais da área pelo país, pois cada doutor que formava, outro campo de estudos se abria e novos pesquisadores iam sendo forjados. 
Com atuação formativa e pedagógica, Guarinello acabou se tornando um ponto de referência nos estudos clássicos nacionais, relevância que sua salutar humildade impede de reconhecer. Não tem quem não o conheça, ou mesmo quem não tenha lido algo de sua produção, dentre os que se dedicam aos estudos da Antiguidade em solo pátrio. Na produção literária, sempre prezou mais a qualidade do que a quantidade. Assim, neste artigo-homenagem, pretendo destacar apenas dois textos de sua lavra.

O primeiro foi publicado em 2003 na revista Politeia, de Vitória da Conquista - Bahia, e intitulado "Uma morfologia da História: as formas da História Antiga". Nele, o autor lapidou uma conferência proferida anteriormente, na qual defendia que o que costumamos denominar de História Antiga, em termos de tempo e espaço, foi sendo elaborada ao longo dos anos, à medida que os historiadores iam definindo o que deveria ser ministrado e/ou aprendido por quem estudava e/ou ensinava a tal História Antiga. Portanto, trata-se de uma construção, de uma formatação, de uma definição de parâmetros que, muitas vezes, adotamos sem qualquer reflexão sobre o porquê de as coisas serem como são. Naturalizamos algo construído culturalmente através dos séculos e que respondeu a inúmeras necessidades antropológicas, culturais e didáticas. Nesse artigo, o professor Norberto Guarinello exerce uma de suas maiores capacidades cognitivas: a desconstrução de parâmetros existentes, que apenas reproduzimos sem qualquer questionamento prévio. Sua metáfora de uma corrida na qual os atletas passam o bastão de um para o outro, como forma de exemplificar o que fazemos com os estudos das sociedades orientais e clássicas em nossas salas de aula (primeiro, estudando Mesopotâmia; depois, Egito; em seguida, Grécia; e finalmente Roma, sem atentarmos para o fato de que essas comunidades se desenvolveram muitas vezes paralelamente, posicionando-as realmente como uma sucessão acumulativa de conteúdos a serem apresentados aos discentes), tornou-se antológica. Não à toa, eu e Luciane Munhoz de Omena resolvemos iniciar nosso primeiro curso remoto a ser oferecido na UFG, devido à eclosão da epidemia do coronavírus, com esse artigo de Guarinello. Num mundo em reconstrução, pareceu-nos adequado começar questionando nossos próprios parâmetros pedagógicos, no que concerne à disciplina que ministramos.

Nos Anais, em dois volumes, do Seminário Internacional "Festa: cultura e sociabilidade na América Portuguesa”, realizado na USP em 1999, encontramos também uma pequena pérola produzida pelo professor Norberto 
Guarinello. Trata-se do penúltimo capítulo do segundo volume, integrante da seção "A Propósito da Festa", em que encontramos a reprodução da comunicação intitulada "Festa, trabalho e cotidiano", que muito nos auxiliou em nossas pesquisas sobre festejos e cerimônias no Mundo Romano Antigo. Convidado a participar do evento, eu imagino Guarinello, historiador da Antiguidade, refletindo sobrecomo poderia contribuir com uma atividade referente às festas ocorridas no ambiente da América Portuguesa. Sua produção acabou transpirando um tom mais teórico, fornecendo ao leitor/ ouvinte reflexões mais conceituais acerca da eclosão dos fenômenos festivos em várias espacialidades e temporalidades. E aí se encontra, em minha opinião, a riqueza de sua produção: ele nos fornece uma conceituação de festa capaz de fomentar vários tipos de trabalhos sobre cerimônias, rituais e festividades em inúmeros tempos e espaços diferentes.

Paul Veyne, no livro Como se escreve a História, publicado inicialmente em 1971, demonstra cabalmente a importância da construção de conceitos para o avanço da elaboração do saber histórico. A ideia de uma história conceitual, na qual cada palavra inserida num relato deva ser entendida como uma opção, que vai além do estilo e do gênero da escrita, e que se impregna de opções cognitivas, metodológicas e teóricas, faz coro com o que foi produzido por Guarinello em seu pequeno texto. Ele começa gerando e oferecendo ao seu público uma definição de festa que pode alicerçar pesquisas em múltiplas áreas e em inumeráveis temas. Verifica-se, assim, um exercício histórico que, a meu ver, demonstra a maturidade de seu criador:

Como define Norberto Guarinello:

Festa é, portanto, sempre uma produção do cotidiano, uma ação coletiva, que se dá num tempo e lugar definidos e especiais, implicando na concentração de afetos e emoções em torno de um objeto que é celebrado e comemorado e cujo produto principal é a simbolização da unidade dos participantes na esfera de uma determinada identidade. Festa é um ponto de confluência das ações sociais cujo fim é a própria reunião ativa de seus participantes. Festa, portanto, produz identidade. [...] Toda festa tem suas próprias regras. [...] $O$ que chamamos de festa é parte de um jogo, é um espaço aberto no viver social para a reiteração, produção e negociação das identidades sociais. Um lapso aberto no espaço e no tempo sociais, pelo qual circulam bens materiais, influência, poder. [...] A festa unifica, 
mas também diferencia, tanto interna quanto externamente. [...] A festa não apaga as diferenças, mas antes une os diferentes. A identidade que cria é uma unidade diferenciada [...]. Toda festa é [,,.] uma estrutura de poder, [...] que se inscreve na memória coletiva e individual dos participantes. (GUARINELLO, 2001, p. 972-974)

Nessas linhas, o professor me forneceu a conceituação que eu precisava para escrever o projeto de pesquisa intitulado "Construindo identidades no Império Romano: festas nos Governos de Septímio Severo e Caracala", com o qual fui beneficiada com a concessão, pelo CNPq, de minha primeira Bolsa de Produtividade, em 2008. Foi um enorme prazer realizar as tarefas e os objetivos definidos nesse projeto. Adorei o tema e a oportunidade de escrever vários trabalhos e proferir múltiplas conferências, no Brasil e no exterior, sobre as festas do mundo romano. Integrei-me em vários debates sobre os festejos antigos e sua relevância política, econômica, social e cultural no interior das sociedades complexas.

Fazendo um breve levantamento de como historiadores e antropólogos tinham, até então, trabalhado com o objeto "festa" (SILVA, 2000, p. 38-39), percebi que a maioria dos trabalhos partia da concepção de que festa era vista como um ato coletivo, ritual, em que aconteciam inversões, subversões, por vezes a instauração do caos, marcado principalmente pela alegria. Os momentos estudados eram, muitas vezes, destacados pela carnavalização social, pelo descarrego de tensões reprimidas, pela suspensão da ordem. Contudo, no mundo romano que eu queria estudar, em várias ocasiões festivas, o que eu identificava era a estruturação de festividades que não se adequavam a essa forma de conceituar "festa". Ou seja, festejos nos quais as principais características eram exatamente a manutenção da ordem, mesmo por sua inversão momentânea, o reflexo de certas posições sociais previamente definidas, a formação de identidades e a construção de memórias coletivas nessas festividades.

Toda comemoração era, antes de tudo, uma forma de comunicação (BURKE, 2002, p. 27), um objeto por excelência no qual se poderia articular a análise das relações que se estabeleciam entre a política, o poder, a propaganda e a memória. As festas continuam a fazer sentir os seus efeitos, mesmo quando já acabaram. Associam, pois, a indivisibilidade e a duração características do sagrado com a divisibilidade do profano. Como ressalta Klaus Bringmann, num artigo sobre os festejos triunfais dos imperadores, 
os romanos não conheceram festas que não fossem ao mesmo tempo religiosas e profanas, visto que todos os atos realizados em nome da comunidade política eram, ao mesmo tempo, feitos visando uma comunidade de culto (BRINGMANN, 1988, p. 67). As festas antigas traçam perspectivas que apontam o passado e o futuro de uma coletividade. Por elas, a comunidade reunia o que ocorria no presente, relembrava o passado e indicava metas para o futuro.

A festa seria, assim, um fenômeno gerador de imagens multiformes da vida coletiva e geraria e/ou indicaria vínculos sociais a serem resgatados e/ou mantidos. Toda comunidade precisa de algo para celebrar, pois toda festa é um tempo consagrado. Normalmente, a festividade comporta uma multiplicidade de atividades de naturezas diversas, mas que se encadeiam e ganham sentido exatamente quando encadeadas, distinguindo a festa de uma simples cerimônia. Embora seja também um espetáculo, a festa distingue-se dele, pois quase sempre exige a participação ativa daqueles que dela participam. Mesmo ser espectador de uma festa é, de certa forma, relacionar-se com todos os presentes, é atuar para a sua realização de alguma maneira (PEREZ, 2002, p. 23-28).

A cerimônia pode ser entendida como um conjunto de atos formalizados, expressivos, detentores de uma dimensão simbólica. Ela é caracterizada por uma configuração espaçotemporal específica, pelo recurso a uma série de objetos, por sistemas de comportamento e de linguagem específicos e por sinais emblemáticos cujo sentido codificado constitui um dos bens comuns de um grupo. A cerimônia é também um ritual, o qual insiste na dimensão coletiva, isto é, ele faz sentido para os que o partilham. Ele tem eficácia social, pois ordena a desordem, dá sentido ao acidental, cria situações de adesão e regula conflitos. A festa é, antes de tudo, um ato coletivo, com um lado sagrado e outro leigo de puro divertimento, e serve ao poder, que deve afirmar-se regularmente no decurso de grandes cerimônias (SEGALEN, 2000, p. 73-74).

A realização de cerimônias públicas, de momentos festivos, é uma forma sofisticada muito antiga de comunicação com objetivo político, pois elas ajudam a manipular a opinião pública, a persuadir através de imagens e a legitimar o mando, sendo, desse modo, um dos vários instrumentos de poder. No desenrolar das festas, divulgam-se mensagens, imagens, símbolos e mitos, que auxiliam no controle social. A linguagem festiva é, sobretudo, imagética, o que explica seu alto poder de persuasão, de busca de 
consentimento e de apoio ao poder, garantindo uma impressão de unidade, fundamental para a manutenção do comando. O poder utiliza meios espetaculares para marcar sua entrada na história (comemorações, festas de todo tipo, construção e reconstrução de monumentos, por exemplo). As manifestações do poder não se coadunam com a simplicidade; a grandeza, a ostentação e o luxo as caracterizam. As emoções tendem a se exacerbar nos espetáculos festivos organizados pelos poderosos. As imagens utilizadas nas festas marcam a identidade dos regimes e dos espetáculos do poder, realizados com o objetivo de mostrar grandiosidade e força política. Nenhum sistema político é mudo. Um poder que não fala pelo décor, pela mise-en-scène, perderia a adesão do grupo de apoio, pois a persuasão reforça a sujeição. Portanto, as festas são signos e fazem parte de um ritual: não há sociedade sem ritual e não há ritual sem festas, pois elas ajudam a legitimar o regime (CAPELATO, 1998, p. 19-59).

O ritual pode ser entendido como um conjunto de atos formalizados, expressivos, detentores de uma dimensão simbólica. Como nos lembra Javier Arce, o ritual não é a máscara do poder, mas é em si mesmo uma forma de poder (ARCE, 1988, p. 242). Toda festividade se insere também no campo econômico, pois as cerimônias se expressam a partir da possibilidade financeira de cada comunidade festiva.

Como o meu objeto de pesquisa tem sido, desde o Doutorado realizado sob a orientação do professor Norberto Guarinello, a estruturação das formas de poder no Mundo Romano Antigo, sob o prisma da constituição de uma cultura política, interessaram-me as maneiras que os homens encontraram para exercer poder uns sobre os outros (de expressarem sua autoridade e de conseguirem atendimento em suas demandas), as formas de ascensão aos cargos criados, as práticas para se conquistar a adesão social, os modos de se opor a esse poder, os jeitos de apresentá-lo como legítimo e legal, e os estratagemas usados para a sua manutenção pelo maior tempo possível. Os rituais e as festas também se transformaram em assuntos cujo interesse tem se mostrado extremamente profícuo para os estudos históricos. A partir da percepção de que num momento festivo ou ritualístico se definem várias formas de interação e de relacionamento social, criando-se hierarquias e estruturando-se formas de expressão de poder, as festividades passaram a ser vistas como objetos históricos por excelência, e necessários para compreensão de nosso amado Mundo Romano Antigo. 
No projeto de pesquisa que apresentei ao CNPq, a partir da concepção norbertiana de festa, propus-me a analisar as festividades realizadas durante os governos dos dois primeiros imperadores severianos: Lúcio Septímio Severo e seu filho e herdeiro Bassiano, vulgo Caracala. Percebi que com o assassinato de Caracala em 217 d.C., a mando de seu prefeito do Pretório, Macrino, realizou-se uma mudança no sentido dos festejos. Enquanto nos dois primeiros governos os príncipes buscaram criar uma justificativa para a ascensão de outra família ao poder, após o assassinato de Pertinax pelos pretorianos, a partir do governo de Macrino, um membro da ordem equestre que não tinha relação direta com a domus severiana, tornou-se necessário praticar cerimônias capazes de criar uma vinculação de Macrino e seu filho e herdeiro Diadumeno com os Severos. E nos governos posteriores de Heliogábalo e Severo Alexandre, buscou-se retomar a vinculação com Septímio e Caracala pela produção de novos tipos de festejos. Assim, defendi que as cerimônias realizadas pelos primeiros Severos compuseram um quadro ritualístico específico, que se diferenciava das cerimônias posteriores em termos de sentido, necessidade e resposta a um contexto também específico.

Durante os governos de Septímio (193-211 d.C.) e Caracala (211-217 d.C.), foram realizadas festividades importantíssimas para a compreensão da organização do poder no Principado. Nos documentos textuais, epigráficos, numismáticos e arqueológicos, pude encontrar informações que, devidamente analisadas, permitiram-me elaborar um quadro dos rituais que foram implementados na confecção das identidades romanas à época.

$\mathrm{O}$ adventus do príncipe nas cidades visitadas, por exemplo, era uma grande festa, não apenas em Roma, mas em todas nas quais o imperador entrava. $\mathrm{O}$ adventus, isto é, a entrada dos governantes romanos nas cidades espalhadas pelo território imperial, era uma prática antiga dos príncipes que o imperador Septímio Severo, na passagem do II para o III século d.C., quis manter viva, pois, como recorda Herodiano, "onde o Imperador se encontra ali está Roma" (HERODIANO. História do Império Romano Após Marco Aurélio, I, 6, 5). Então, receber o príncipe com festa era como demonstrar a aceitação do domínio imperial romano, era fazer festa para a própria Roma encarnada no soberano. Era um momento no qual o centro visitava a periferia e no qual a unidade representada pelo príncipe se encontrava com a grande diversidade que marcava o Império Romano. 
Para Sabine G. MacCormack, na cerimônia do adventus passava-se a imagem do consensus omnium ideal, fundamental para legitimar o governante, pois pobres e ricos, senadores e plebeus, civis e militares participavam da mesma alegria pela chegada do soberano. Tratava-se de um esplêndido teatro, no qual o imperador estabelecia relações de troca com os homens e com os deuses. Com os homens, pelos benefícios que concedia após a acolhida; com os deuses, pelos sacrifícios que realizava ao longo da recepção (MACCORMACK, 1981, p. 17-23). A procissão de boas-vindas servia, desse modo, para realçar a dignidade e a autoridade da pessoa que entrava na cidade. No Principado, somente o príncipe passou a ter direito ao adventus, o que, mais uma vez, permite aproximar esse evento festivo do Triunfo, que também só podia ser dado ao imperador, pois, em ambos os casos, o príncipe (também imperador) era considerado como general vitorioso e chefe de Estado. Era a possibilidade de ter a presença de um ser cada vez mais distante de seus súditos, só conhecido por intermédio de moedas e de estátuas. Esse cerimonial foi se desenvolvendo tanto que, no IV século d.C., a chegada do imperador era vista como a de um deus praesens (MACCORMACK, 1972, p. 721-752).

Os documentos revelam que havia celebrações na chegada e na partida das cidades visitadas. Na chegada, como forma de agradecer a presença do imperador, e na partida, para desejar sucesso ao empreendimento a ser realizado. As ovações nesses dois momentos integravam a mesma categoria de manifestações públicas das quais faziam parte as aclamações, os vota e as saudações. Eram formas de se louvarem o caráter e os atos dos soberanos, sendo que, em troca dessa manifestação pública de apoio, esperava-se que o soberano se manifestasse, distribuindo algum tipo de benesse. De acordo com H. Mattingly, as cerimônias de adventus eram momentos privilegiados para a formulação dos vota publica, pedindo-se às divindades a proteção dos príncipes, além da tradicional festa de 3 de janeiro, na qual se dedicavam pedidos aos deuses em favor dos soberanos e de suas famílias (MATTINGLY, 1950, p. 156).

Caracala, por sua vez, também executou, ao longo de seu governo, várias cerimônias de adventus memoráveis, procurando viajar pelo território imperial e verificar as relações com as províncias, o moral das tropas e a corrupção dos magistrados locais. Por exemplo, após a morte de Severo e a vitória sobre os bretões, Caracala voltou para Roma e foi recebido com um grandioso adventus, descrito por Herodiano (História do Império Romano Após Marco Aurélio, IV, 1, 3-4). 
Nessas festas, comemoravam-se as vitórias sobre os povos invasores, com a presença da plebe, dos senadores e dos magistrados, a organização de saudações e de cerimônias para marcar a presença dos líderes entre seus súditos. A cidade se movimentava e se organizava para recepcionar a chegada dos Augustos, responsáveis por manterem a unidade do Império.

Três grandes cerimônias públicas marcaram o governo de Septímio: a apoteose de Pertinax, os Jogos Seculares, que comemoravam a Fundação de Roma, e os decennalia do imperador, isto é, a comemoração dos dez anos de governo do príncipe. Pude analisar cada uma delas ao longo desses anos e publicar minhas conclusões de pesquisa em vários suportes, como informa meu Lattes. Como fundador de uma nova dinastia, após um período de marcante guerra civil, Severo sentiu a necessidade de expor publicamente sua vitória sobre os outros concorrentes ao comando imperial e a imagem de unidade, que devia compor o cenário político romano. E a realização de festas era uma forma tradicional de demonstrar a potência e a importância de Roma e de seus soberanos. No governo de Caracala, quando no início o divide com seu irmão Geta, e após o seu assassinato, também se identifica nas fontes o relato de várias cerimônias, analisadas quando inseridas num quadro ritual capaz de dar sentido à sua realização enquanto instrumento de poder e fator de criação de identidades. Por exemplo, o ritual de apoteose de Septímio, capaz de transformar Caracala em filho de uma divindade.

Em todas essas festas, as cidades se engalanavam, se preparavam por meio de construções. Algumas delas resistiram ao tempo. Outras conhecemos por intermédio das moedas cunhadas para comemorar e publicizar a construção. Ou mesmo de epígrafes que adornavam suas partes e informavam, muitas vezes, a razão de sua edificação. Desse modo, foi fundamental integrar o estudo dos relatos escritos a peças arqueológicas produzidas no afã das festividades. Com esta necessidade, voltei a estudar artefatos vindos da cultura material, que haviam marcado meu primeiro contato acadêmico com o professor Norberto Guarinello.

Como afirma Arnaldo Momigliano, as estátuas, os templos, os sacerdotes, os jogos, os sacrifícios e todos os atos cerimoniais, todas as festas que se executavam em honra do imperador, ajudavam a fazê-lo presente: também ajudavam o povo a expressar seu próprio interesse na conservação do mundo em que viviam (MOMIGLIANO, 1992, p. 170). Comemorar o governante era também festejar a manutenção da situação vigente. Assim, quando analisei as festas e celebrações executadas no 
mundo romano, no desenvolvimento desse projeto, suscitado e formulado a partir daquela sucinta conceituação norbertiana de festa, pude perceber como o espaço festivo era utilizado para divulgar a imagem positiva do soberano e para gerar um sentimento de pertencimento, capaz de viabilizar a fomentação de identidades, prática esta que permaneceu presente até o mundo contemporâneo.

Essa validação de nossos estudos das sociedades antigas pelo seu entrelaçamento com o que ainda nos causa interesse na contemporaneidade é, inclusive, uma das marcas dos trabalhos de Norberto Guarinello ao longo de sua carreira. Sua preocupação com a relevância atualizada de suas temáticas e com a garantia de seu potencial historiográfico marca sua produção como um todo. Seu interesse constante em relação a objetos atuais acabou por manter o frescor de sua produção bibliográfica, que, como enfatizei anteriormente, não se destaca pelo volume, mas pela musculatura e pela profundidade alcançadas pelas análises estabelecidas. Seu talento para a "conceitualização" dos processos históricos, escolhendo os termos adequados para explicar um fenômeno de forma integral e tornando-o de fácil compreensão, sempre me chamou a atenção.

Uma característica que frequentemente compartilhei com o meu antigo orientador foi o interesse por vários documentos de múltiplos períodos históricos, o que levou ambos a orientarem temáticas vinculadas tanto ao mundo grego quanto ao mundo romano. Não só orientamos como escrevemos sobre assuntos que se estendem das epopeias homéricas aos bispos e poetas da Antiguidade Tardia. Essa elasticidade, ao mesmo tempo que provocou críticas de muitas agências de fomento, certamente nos proporcionou grandes momentos prazerosos. Quando criticada abertamente pela falta de foco em meus grupos de pesquisa, sempre aventei minha vinculação ao professor Norberto Guarinello: faço como ele e pronto.

Portanto, neste artigo-homenagem, acredito ter podido expressar um pouco do enorme carinho que tenho pelo mestre e retribuir as inúmeras gentilezas acadêmicas que ele me ofereceu ao longo dos anos. Se você, leitor, ainda não teve a possibilidade e o prazer de se entreter com algum texto norbertiano, sua formação não está completa. Aprenda a exercer seu potencial crítico e sua veia investigativa a partir da produção acadêmica e literária de Norberto Guarinello. Pareceu-me plenamente justificável abordar o tema festa quando nos reunimos neste dossiê para comemorar, não a aposentadoria de um amigo (não se engane), mas a permanência indelével 
da ação do mestre na formação de todos nós. Tornou-se impossível entrarmos em contato com ele e não sairmos marcados pela sua genialidade acadêmica e pela sua competência pedagógica. Mais que um formador de docentes, eu homenageio, neste espaço, um forjador de mentes críticas e de personalidades investigativas.

\section{Documentação escrita}

ERODIANO. Storia dell'Impero Romano dopo Marco Aurelio. Trad. Filippo Càssola. Firenze: Sansoni, 1967.

HERODIANO. Historia del Imperio Romano después de Marco Aurélio. Trad. Juan J. Torres Esbarranch. Madrid: Gredos, 1985.

HÉRODIEN. Histoire de l'Empire Romain après Marc-Aurèle. Trad. Denis Roques. Paris: Les Belles Lettres, 1990.

\section{Referências bibliográficas}

ARCE, Javier. Funus Imperatorum. Madrid: Alianza, 1988.

BRINGMANN, Klaus. El triunfo del emperador y las Saturnales de los esclavos en Roma. In: SCHULTZ, Uwe. (org.). La fiesta: una Historia Cultural desde la Antigüedad hasta nuestros días. Madrid: Alianza, 1988, p. 65-75.

BURKE, Peter. O mundo como teatro. Lisboa: Difel, 2002.

. A fabricação do rei. Rio de Janeiro: Jorge Zahar, 1994.

CANNADINE, David; PRICE, Simon (eds.). Rituals of royalty. Cambridge: University Press, 1987.

CAPELATO, Maria Helena. Multidões em cena. Campinas: Papirus, 1998.

GONÇALVES, Ana Teresa Marques. A arte poética a serviço do proselitismo cristão: relendo os poemas de Aurélio Prudêncio Clemente (séculos IV/V). Jundiaí: Paco, 2020.

GUARINELLO, Norberto Luiz. Uma morfologia da História: ass formas da História Antiga. Politeia, Vitória da Conquista, v. 3, n. 1, p. 41-61, 2003.

. Festa, trabalho e cotidiano. In: JANCSÓ, István; KANTOR, Íris (orgs.). Festa: cultura e sociabilidade na América Portuguesa. São Paulo: Hucitec/Imprensa Oficial, 2001, p. 969-978. v. 2.

MACCORMACK, Sabine G. Art and ceremony in Late Antiquity. Berkeley: University of Califórnia Press, 1981. 
. Change and continuity in Late Antiquity: the ceremony of Adventus. Historia, Wiesbaden, v. 21, p. 721-752, 1972.

MATTINGLY, Harold. Roman coins. London: Methuen, 1936.

. The Imperial Vota. Proceedings of the British Academy, London, v. 36, p. 155-195, 1950.

MOMigliAnO, Arnaldo. De paganos, judios y cristianos. México: FCE, 1992.

PEREZ, Lea Freitas. Antropologia das efervescências coletivas. In: PASSOS, Mauro (org.). A festa na vida. Petrópolis: Vozes, 2002, p. 15-58.

SEGALEN, Martine. Ritos e rituais. Lisboa: Europa-América, 2000.

SILVA, Maria Manuela de Souza e. A historiografia descobre a "festa". Hélade, Rio de Janeiro, v. 1, n. 1, p. 38-52, 2000.

TEJA, Ramon. Il Cerimoniale Imperiale. In: MOMIGLIANO, Arnaldo; SCHIAVONE, Aldo (dirs.). Storia di Roma. Torino: Giulio Einaudi, 1993, p. 613-642. v. 3, n. 1.

VEYNE, Paul. Como se escreve a História. Brasília: Ed. UnB, 2008. . O inventário das diferenças. Lisboa: Gradiva, 1989. . A História Conceitual. In: LE GOFF, Jacques; NORA, Pierre (orgs.). História: novos problemas. Rio de Janeiro: Francisco Alves, 1976, p. 48-95. 